\title{
Los ecos de las trece colonias. De los impuestos con representación a la participación en los impuestos*
}

\author{
Juan Camilo Rúa Serna**
}

\section{Resumen}

El artículo se propone mostrar cómo ha sido la participación de la sociedad civil en la estructuración de la capacidad fiscal del Estado colombiano. Para ello se revisan procesos de constitucionalidad en los que se hayan demandados normas fiscales, para determinar el nivel de incidencia de los mecanismos de participación ciudadana en la capacidad tributaria del Estado. Mediante análisis básicos de estadística descriptiva y análisis de contenido de los documentos preparatorios de la Constitución Política, se llega a la conclusión de que herramientas de participación ciudadana como la acción pública de inconstitucionalidad han abierto importantes oportunidades para la destrucción y modificación de normas tributarias, lo que sería impensable bajo una democracia estrictamente representativa.

\section{Palabras clave}

Participación Política; Política Fiscal; Acción de Constitucionalidad; Democracia; Colombia.

Fecha de recepción: julio de 2018

- $\quad$ Fecha de aprobación: noviembre de 2018

\section{Cómo citar este artículo}

Rúa Serna, Juan Camilo. (2019). Los ecos de las trece colonias. De los impuestos con representación a la participación en los impuestos. Estudios Políticos (Universidad de Antioquia), 54, pp. 82-105. http://doi.org/10.17533/udea.espo. n54a05

\footnotetext{
* Este artículo es producto de la investigación El papel de la acción pública de inconstitucionalidad en las reformas tributaria de Colombia, 1992-2017, adelantada bajo la línea de investigación Participación ciudadana y DESC del Laboratorio de Derechos Económicos, Sociales y Culturales (DescLAB), Colombia (https://www.desclab.com/2.

** Abogado y Politólogo. Investigador asociado del Laboratorio de Derechos Económicos, Sociales y Culturales (DescLAB), Colombia. Correo electrónico: juancamiloruas@gmail.com Orcid: https:// orcid.org/0000-0003-3877-168X
} 


\title{
Echoes from the Thirteen Colonies. From Taxation with Political Representation to Public Participation on Taxation
}

\begin{abstract}
The article aims to show the role of public participation in the structuring of the fiscal capacity of the Colombian State. For this purpose, constitutionality processes are reviewed in which fiscal rules have been demanded, in order to determine the level of incidence of citizen participation mechanisms in the tax capacity of the State. Through basic analysis of descriptive statistics, and content analysis of the preparatory documents of the Political Constitution, it is concluded that citizen participation tools, such as public action of unconstitutionality, have opened important opportunities for the destruction and modification of tax regulations, which would be unthinkable under a strictly representative democracy.
\end{abstract}

\section{Keywords}

Political Participation; Fiscal Policy; Constitutionality Action; Democracy; Colombia. 


\section{Introducción}

El hombre está fuera de sí, exige ver al supervisor, al gerente, a los miembros de la junta directiva, al dueño del negocio. Le dice a la cajera que no piensa pagar el IVA, que le cobre el producto sin ese impuesto que, según él, será destinado a las FARC. Se niega — vocifera- a comprarle carros y aviones a Timochenko. Para resumirlo, asegura que no piensa pagarle el IVA a una empresa que está aliada con el terrorismo (Publimetro, 2017, noviembre 11). Es la voz de un hombre que se ve a sí mismo en el cumplimiento de un deber cívico. La escena nos recuerda una de esas viejas citas que, salvando el abismo del tiempo, nos siguen hablando: la historia, se repite dos veces, la primera como tragedia y la segunda como comedia (Marx, 2009, p. 1). Y aquí, detrás de lo pintoresco, se puede encontrar la repetición de viejas disputas ideológicas sobre la evasión fiscal.

Esta escena se viralizó durante las discusiones del plebiscito de 2016 sobre los acuerdos de paz con la guerrilla de las FARC en el gobierno Santos. Los debates fueron intensos; la campaña, agitada, álgida, emocional. Tanto los defensores del No como los defensores del Sí sobredimensionaron, exageraron, amañaron. Votar Sí, aseguraban los primeros, convertiría a Colombia en otra

[ 84 ] Venezuela, en una reedición del socialismo soviético más cruel; votar No, afirmaban los segundos, regresaría al país, sin boleto de regreso, a la guerra sin cuartel, a la sangre desbordada y a los llantos desgarrados. Así que la escena del objetor fiscal, en ese contexto, puede analizarse desde varios puntos de vista: los niveles de desinformación en el país, la incertidumbre frente al posconflicto y los retos para la reconciliación parecen cuestiones obvias y hasta urgentes. Tan obvias, que un problema de fondo podría pasar desapercibido: la relación entre participación e impuestos.

El personaje de esta historia se niega a que sus impuestos sean invertidos en una política pública con la que no está de acuerdo. En últimas, podría verse como un objetor fiscal que desea fijar la destinación exacta de sus contribuciones impositivas. Se trata de un deseo que va en contravía de un límite que ha sido relativamente claro en los alcances de la participación ciudadana en las decisiones políticas: la capacidad fiscal. Una razón más o menos lógica ha ayudado a establecer dicho límite: si se deja en manos de los ciudadanos la decisión sobre pagar o no pagar impuestos posiblemente decidirían no pagarlos, lo que terminaría por debilitar la ya débil capacidad fiscal del Estado. Sin embargo, cabe preguntarse si los mecanismos de 
participación ciudadana que consagró la Constitución de 1991 han ayudado a fortalecer la capacidad de la sociedad civil para incidir en la forma en la que se estructuran y se organizan los impuestos en Colombia.

De allí surgió una pregunta de investigación clave: ihan permitido los mecanismos de participación fortalecidos por la Constitución Política de 1991 que los ciudadanos intervengan efectivamente en la modificación de normas tributarias sin tener que pasar por el filtro de sus representantes? La tesis que se defiende en este artículo es que esas herramientas de participación política directa sí han permitido que los ciudadanos modifiquen y destruyan normas tributarias que, de otra manera, no habrían podido cambiar en el marco de una democracia puramente representativa. El derecho, como escenario de guerra ritual (Valencia, 1987, p. 46), ha permitido continuar las luchas del siglo xix por la definición de las dimensiones y alcances de la capacidad fiscal del Estado.

La lucha por la definición de la capacidad estatal hunde sus raíces en una historia de inestabilidad y de fragilidad fiscal. Plantear la evasión de un impuesto como si fuera la expresión de un deber cívico no es una maniobra novedosa. Colombia, después de la independencia, se vio enfrentada a las expresiones de una larga tradición de resistencia a la tributación (Deas, 1980, p. 148). Los débiles gobiernos republicanos, sin los mecanismos de presión coloniales que tuvieron que abandonar para iniciar un proceso de modernización, se vieron en la necesidad de embrollarse en constantes disputas y negociaciones con unas élites regionales y locales pocas veces sumisas y ajustadas a los deseos del poder central (Palacios, 1980; Clark, 2007).

Esta fragilidad fiscal fue una de las mayores fuentes de inestabilidad política y fue uno de los factores que ocasionó que sucesivas constituciones se reemplazaran las unas a las otras: cada nuevo texto constitucional era tan débil y flaqueaba tan rápido como el anterior (Irigoin, 2016, p. 202). La historia constitucional de Colombia se construyó sobre la base de constituciones que, más que acuerdos políticos sobre la estructura y distribución del poder, con vocación de permanencia en el tiempo, eran verdaderas cartas de batalla, capitulaciones jurídicas que reflejaban los resultados de las guerras (Valencia, 1987). Así, las reformas fiscales de las primeras décadas del siglo XIX, con la dificultad para establecer impuestos directos y aumentar el recaudo de ingresos, no solo no construyeron capacidad fiscal (Irigoin, 2016, p. 189), sino que se implementaron en un contexto de volatilidad constitucional. 
Esta historia de disputas en torno a los impuestos puede ser, en buena medida, lo que explica que en el siglo xx las discusiones públicas sobre las propuestas tributarias fueran mínimas y las decisiones fiscales terminaran haciéndose, generalmente, en la sombra, «de tal modo que lo que se decidiera no [fuera] conocido por los ciudadanos» (Kalmanovitz, 2016, p. 13). De esta manera, la cuestión fiscal ha terminado por ligarse a una democracia de tipo representativo en la que la fijación de los impuestos depende de las discusiones y decisiones de quienes fueron elegidos para representar a la ciudadanía y no directamente de la ciudadanía.

De hecho, algunas líneas de investigación han señalado una relación de causalidad entre algunos tipos de impuestos y mayores niveles de democracia representativa (Ross, 2004). El argumento es que la necesidad de subir impuestos relacionados con servicios estatales obligaría a que los gobiernos se vuelvan más democráticos. La idea se asienta con fuerza en la historia de los avances representativos en Estados como Francia, España e Inglaterra. El último caso es especialmente relevante, pues la admisión del derecho del Parlamento a legislar y su capacidad para enjuiciar abusos y tomar decisiones sobre la política nacional fueron prerrogativas prácticamente compradas a Edward I y a Edward III (Stubbs, 1895, p. 599). Los argumentos que llevaron a esta progresiva democratización fueron retomados después por las colonias británicas en América para oponerse al establecimiento de impuestos directos sobre el azúcar. El tercer postulado de The Declaration of Rights of Stamp Act Congress es contundente: ninguna contribución fiscal debe ser impuesta sin el consentimiento, que puede darse de manera personal o a través de los representantes.

A partir de estas ideas se ha señalado que esa demanda política de exigir que ningún impuesto sea establecido sin representación se manifiesta, además, en la realidad política de que entre menores sean los niveles de imposiciones fiscales, menor razón tiene la sociedad civil para demandar representación (Huntington, 1991, p. 65). En suma, la literatura se ha preocupado por ver cuáles son las relaciones entre impuestos y democracia representativa, es decir, por estudiar las formas en la que los asuntos tributarios inciden y se reflejan en las lógicas de actuación de los órganos de representación política. Los principios políticos y conceptuales que se encuentran bajo la expresión «No hay impuestos sin representación» han terminado por dominar las reflexiones que se encuentran en la literatura sobre impuestos y sociedad civil. 
En ese contexto, la lectura aquí propuesta adopta una nueva línea de reflexión que va más allá de la democracia representativa para preguntarse por las dinámicas que se dan en el marco de una democracia con mayores niveles e instrumentos de participación ciudadana. En ese sentido, la imposición de cargas tributarias, en el contexto de una democracia participativa, hace que los ciudadanos, más que exigir mayor representación, se vuelvan más activos en la utilización de los instrumentos de participación política directa.

\section{Metodología}

La investigación partió de una metodología mixta en la que se combinaron estrategias cuantitativas y cualitativas, para lograr construir un conocimiento integral sobre la incidencia de la participación ciudadana en la reconfiguración de la capacidad fiscal del Estado colombiano. La razón de esta elección se debe a que resulta útil partir de algunos datos cuantitativos que ayuden a dimensionar la participación y a partir de allí ofrecer interpretaciones desde lo cualitativo. Para ello se revisaron 623 demandas de constitucionalidad sobre 37 leyes tributarias expedidas entre 1989 y 2016 . Esta elección se debe a una razón de accesibilidad sobre la información: son las demandas disponibles en la página web de la Corte Constitucional. De estas se eligieron los procesos finalizados, es decir, que terminaron en sentencia o en archivo. Allí se revisaron 468 procesos: 68 sobre el Estatuto Tributario (Decreto 624 de 1989) y 400 sobre reformas estructurales. A partir de esta revisión se aplicó un ejercicio de estadística descriptiva básica para identificar tendencias y efectividad de las decisiones. De igual forma, se hizo un análisis de contenido de las providencias para identificar, con mayor profundidad, información sobre participación de algunos actores concretos.

Esta información, además, se complementó con una estrategia de investigación documental, en la que se revisaron los antecedentes de la Constitución de 1991 para estudiar los discursos que se elaboraron al interior de la Asamblea Constituyente en materia de política fiscal y democracia. Para ello se revisaron actas y proyectos de articulado publicadas en la Gaceta Constitucional. Con ello se hicieron análisis de discurso y se identificaron líneas argumentativas sobre el papel de la participación ciudadana en materia de impuestos. Esta investigación documental resultó particularmente relevante para la construcción del contexto histórico y político en el que se ha enmarcado la apropiación de la acción pública de constitucionalidad como mecanismo de participación para hacer de la política fiscal un espacio de 
disputa política e ideológica. Esto se debe, en buena medida, al hecho de que los documentos son expresiones y registros de procesos sociales que dan cuenta de resultados y acciones llevadas a cabo en la realidad social (MacDonald y Tipton, 1995, p. 188). Es decir, los documentos son las huellas que dejan tensas y densas disputas entre actores complejos con distintos intereses y con diferentes capacidades de movilización de dichos intereses.

\section{Participación e impuestos: un marco teórico}

La deliberación y la participación han redefinido los contornos de lo que implica un régimen democrático. Las ciudadanías tienen deseos cada vez más intensos de complementar las posibilidades que les dan la representación democrática; es decir, de ir más allá de lo que los políticos que eligen puedan o no hacer. Precisamente por ello, es posible ver que hay un creciente número de iniciativas y prácticas sociales que buscan la creación de nuevos espacios cuya finalidad última es que los ciudadanos amplíen los márgenes mediante los cuales pueden incidir de forma directa en las decisiones políticas que afectan su vida (Pimbert y Wakeford, 2001, p. 23). Esto se debe, en buena medida, a un rechazo generalizado de la democracia como una mera competencia electoral que se define a través del voto ciudadano. Las

[ 88 ] elecciones competitivas, claro está, hacen parte del sistema democrático, pero no es su único elemento definitorio.

Pueden identificarse cuatro principios básicos que definen a un régimen democrático: la existencia de elecciones libres y competitivas que impidan que a través de la imposición o el fraude se determine quién será elegido; sufragio universal para garantizar que todos los ciudadanos participen del proceso; protección a los derechos civiles y políticos, entre los que se encuentran la libre expresión, la libertad de prensa, el derecho a organizarse, entre otros; finalmente, el ejercicio real del poder en cabeza de quienes lo detentan, que busca impedir que exista un poder oculto que, tras un velo, gobierne sin haber sido elegido (Mainwaring, Brinks y Pérez, 2007, pp. 125128). De estos elementos, uno de los más relevantes es el de la garantía de los derechos civiles y políticos, pues es el que permite que el sistema sea democrático de manera permanente y no solo en los tránsitos electorales. Esta idea de la democracia señala un régimen que opera no solo cuando eligen a los representantes, sino que se extiende sobre la totalidad de la existencia social. Es precisamente por ello que se le da a la ciudadanía el papel más importante dentro de una democracia y se incluye dentro de sus elementos 
definitorios la existencia de una sociedad civil viable y con capacidad de deliberación y de organización (Schmitter y Karl, 1991, p. 75).

La importancia de la participación se ha resaltado en virtud de las críticas hechas a la democracia representativa, a la cual se le han identificado y señalado muy fuertes debilidades. De hecho, la idea misma de representación política ha sido cuestionada (Schweber, 2016, p. 395), al argumentarse que implica, en esencia, una limitación. Se agitan en dicho concepto cuestiones profundamente normativas sobre lo que se incluye o se excluye. Un segundo tipo de críticas le apunta a que la representación encuentra un límite insalvable en su incapacidad para dar cuenta de los complejos intereses que se generan y se cruzan y se encuentran en sociedades cada vez más diversas (GopalJayal,2009, p. 326), con grupos poblacionales con historias de ventajas y desventajas muy variadas. Finalmente, un tercer tipo de críticas señala que la representación encuentra serias limitaciones en el marco de las sociedades globalizadas, en las que se pone en duda el papel y relevancia del Estadonación, en su concepción tradicional como actor unitario y cohesionado (Bonanno, 2000, p. 306). La participación responde a estos límites y busca ensanchar los espacios en los que la democracia se vive como realidad. Uno de esos espacios es el de la política fiscal.

Los estudios críticos sobre las políticas fiscales han procurado desmontar una de sus premisas más importantes, una que, durante muchos años, las han alejado del debate democrático: su supuesta neutralidad política. Las políticas fiscales han intentado, de manera intencional, omitir el hecho cierto y evidente de que quienes pagan tributos tienen identidades sociales y políticas concretas, y los han visto solo a partir de los rasgos de sus ingresos (Knauer, 2014). Es decir, las políticas fiscales han omitido la complejidad y las diversidades sociales, culturales y políticas de las comunidades a las que gravan y las han visto solo como agentes económicos: qué pueden producir y qué ingresos perciben por ello. Es decir, ha sido una política constantemente indiferente al impacto que los impuestos pueden generar en unas disparidades ya existentes. Con ello no se han reconocido las vías mediante las cuales la política fiscal puede agravar o remediar esas disparidades (Murphy y Nagel, 2002).

En este sentido, el presupuesto teórico de este artículo busca poner en duda dicha neutralidad y revelar las luchas políticas que se hacen a través de la acción pública de inconstitucionalidad. Es decir, la política fiscal no es un 
campo políticamente neutral en el que las cuestiones se decidan a partir de argumentos puramente técnicos, por el contrario, se trata de un espacio de disputa política e ideológica en el que la ciudadanía hace uso de los distintos mecanismos de participación que prevé la Constitución, en este caso, la acción de inconstitucionalidad. Con ello, nos acercamos a las múltiples críticas que ha recibido el presupuesto de la neutralidad de la política fiscal que se han venido construyendo desde diversas perspectivas, que van desde la teoría queer (Cain, 1991; Knauer, 1998), la teoría racial crítica (Moran y Whitford, 1997), las teorías del feminismo legal (Alstott, 1996) y los estudios críticos de discapacidad (Seto y Buhai, 2006). En conjunto, estos aportes han intentado mostrar que las políticas fiscales reflejan y refuerzan disparidades de género, de sexo, de orientación sexual, de raza y pertenecía étnica, de condición socioeconómica, de edad y de discapacidad. El acercamiento crítico a la política fiscal y la identificación de las prácticas de participación frente a ella permiten, por lo tanto, identificar, comprender y divulgar focos de resistencia frente a su falsa neutralidad y darle dimensiones al contorno de la lucha política que allí se agita.

Al recuperar los contornos de dicha lucha política, se puede reflexionar sobre las múltiples identidades políticas y las subjetividades que están en juego

en las decisiones concernientes a la tributación y pensar en un concepto de «ciudadanía fiscal» (Morgen y Erickson, 2017), en virtud del cual se establecen discursos, prácticas y significados en relación con la definición y el pago de impuestos como una forma concreta en la que nos relacionamos con el Estado, con la sociedad y con la comunidad. Es decir, el pago de impuestos se vuelve una de las expresiones más claras de un contrato social, mediante el cual se generan obligaciones y expectativas como miembros de una comunidad imaginada (Mehrotra, 2015). Es allí que se vuelve crítico pensar en las formas en las que los ciudadanos pueden disputar y negociar los contornos de dicha «ciudadanía fiscal», y es allí que se vuelve crítico pensar en el papel de la participación ciudadana.

La participación ciudadana se concibe, desde esta perspectiva, como una amplia práctica mediante la cual los ciudadanos de una comunidad política participan en la fijación de la agenda, en la toma de decisiones y en las actividades de política de las organizaciones y las instituciones que tienen interés en el desarrollo de una sociedad dada (Creighton, 2005, p. 7). Es decir, se trata de un proceso mediante el cual quienes no detentan un poder político dentro de una estructura estatal buscan incidir en la conformación, 
diseño e implementación de las políticas que los afectan. Es una práctica que puede desarrollarse en distintos niveles (Rowe y Frewer, 2005). Se encuentra, en primer lugar, un nivel de comunicación pública, en el que hay un flujo de información que fluye en una vía: de las entidades estatales hacia la sociedad civil, de la que no se espera ningún tipo de retroalimentación. En un segundo nivel, se pasa a la consulta pública, en la que la información va de los ciudadanos a las entidades estatales. No hay un diálogo, es decir, no hay intercambios, pero las ciudadanías pueden producir ideas, sugerencias, recomendaciones y propuestas. Finalmente, se tiene el último nivel, el de participación, en el que sí se encuentra un diálogo, en el sentido de que se producen transformaciones o estas son posibles. Este diálogo no se debe entender exclusivamente en términos de intercambio discursivo, sino en términos de la capacidad de las ciudadanías. Mediante la participación, su agencia y autoeficacia alcanzan un nivel que les permite generar cambios en las políticas, fijar agendas, determinar sentidos de la actuación y modificar diseños institucionales. Es precisamente este nivel en el que se mueve en este artículo.

Este trabajo se inscribe en la necesidad de mostrar las dimensiones y los alcances que ha tenido la acción pública de inconstitucionalidad para poner la participación ciudadana al servicio de la democracia y, particularmente, para romper la falsa neutralidad tributaria y hacerla un campo de disputas políticas e ideológicas. El presupuesto teórico básico no es otro que gracias a este mecanismo de participación, mediante el cual la ciudadanía puede aportar a la defensa del ordenamiento constitucional, se abren posibilidades para que se modifique la política fiscal, la cual, en términos generales, ha estado por fuera del alcance de los mecanismos de democracia participativa. No ha sido, claro está, un camino fácil.

\section{La jurisdicción constitucional como escenario de confrontación}

La Constitución Política de 1991 es la respuesta a una crisis de legitimidad. El fortalecimiento de mecanismos de participación directa buscaba repeler el declive de una democracia representativa cada vez más frágil e inoperante (Guzmán, 2011, p. 30). Una de las tareas de los constituyentes de 1991 era reestructurar el aparato institucional para lograr un verdadero diálogo entre el Estado y la sociedad civil (Uribe, 1995, p. 79). Se consagraron múltiples herramientas jurídicas y políticas que facilitaran la incidencia de la ciudadanía 
en las decisiones que los afectan. Así, mecanismos como la consulta popular nacional (artículo 104) y local (artículo 105), la iniciativa legislativa popular (artículo 155) y el referendo derogatorio (artículo 170) permiten que cualquier ciudadano intervenga en la transformación del sistema político en el que vive.

De estos mecanismos, uno que interesa especialmente es el referendo derogatorio, pues permite a un grupo de ciudadanos equivalente a la décima parte del censo electoral convocar a un referendo para derogar una ley. Así planteado, puede resultar una acción ideal para tumbar normas tributarias con las que no se está de acuerdo. Sin embargo, el artículo 170 prohíbe explícitamente que dichos mecanismos se apliquen sobre normas relativas a materias fiscales y tributarias. La nueva constitución planteó, entonces, una democracia participativa, pero con límites definidos.

La definición de este límite no tuvo mayor discusión en los debates de la Asamblea Nacional Constituyente (ANC), como se observa a partir de la revisión de las ponencias y proyectos de preparación para las plenarias. Aunque algunos constituyentes se preocuparon por discutir la importancia de ampliar los alcances de la democracia (Esguerra y Arias, 20 de mayo de 1991), y de hacerlo a temas tan diversos como la seguridad social y los servicios [ 92 ] públicos (Garcés, 19 de febrero de 1991), por buscar que los ciudadanos tuvieran un espacio para ser realmente oídos y proponer fórmulas para la construcción de mejores leyes (Lleras y Mejía, 8 de marzo de 1991), y por superar la crisis de participación (Trujillo, 8 de marzo de 1991; Galán, 8 de marzo de 1991), no se hizo el ejercicio de cuestionar o debatir el alcance de la participación directa en materia tributaria. La única ponencia en la que se aborda la cuestión, presentada por la bancada del M-19 (Navarro et al., 7 de marzo de 1991, p. 7) solo sostiene, sin desarrollarlo, que la cuestión tributaria debe permanecer en cabeza «de los cuerpos de representación popular».

Las gacetas constitucionales también muestran un marcado desinterés por la cuestión. Las discusiones giraron, en su mayoría, en torno a cuestiones de contenido jurídico, a la inmovilidad de las reformas constitucionales y al establecimiento de cláusulas pétreas (ANC, 1991, febrero 18; 1991, febrero 19a; febrero 19b; 1991, marzo 4; 1991, marzo 5; 1991, marzo 15). Tan solo una de las gacetas identificadas como relevantes (ANC, 1991, mayo 4) se refiere a la aplicación del referendo derogatorio en materia tributaria, y lo hace de una manera muy tangencial: no hay debate ni reflexiones al respecto, solo la idea de que es una restricción que debe permanecer, pues varios países de la región la consagran. 
A pesar de estos limitantes a la democracia participativa en materia de contribuciones fiscales, la Constitución Política fortaleció otro mecanismo que ha resultado central para dar peso al consentimiento de los ciudadanos: la acción pública de inconstitucionalidad. Mediante ella, cualquier ciudadano puede demandar cualquier norma con rango legal, tanto por vicios materiales como procedimentales (artículo 241). No se trata, claro, de una innovación de esta Constitución, pero sí del derecho colombiano, pues una reforma constitucional de 1910 creó un control constitucional difuso del que pueden hacer parte los ciudadanos y que no fue previsto por la Constitución de 1886 (Mendieta, 2010). El aporte de la nueva Constitución, en todo caso, fue la creación de una jurisdicción propia y la clarificación de las reglas de procedimiento. Estos avances han hecho que la acción sea más cercana para la ciudadanía.

Ha sido en el escenario de la jurisdicción constitucional y mediante la acción pública de inconstitucionalidad que se ha venido recreando la lucha contra la expansión de las potestades fiscales del Estado colombiano. El derecho puede verse allí como un escenario de guerra reglada, de confrontaciones rituales en las que el poder se define y se construye. «[Se traslada] al lenguaje ceremonial del debate forense los conflictos de poder entre los órganos del Estado, entre los partidos gobernantes y sus fracciones, y entre estas instancias y los sectores dominados de la población civil» (Valencia, 1987, p. 45). Es decir, el derecho no es un mero resultado del poder, sino que es espacio en el que este se forma y se transforma.

Es allí donde la acción pública de constitucionalidad adquiere un papel con la mayor relevancia. Si bien se trata de un mecanismo que no se encuentra listado en la Ley 134 de 1994 ni en la Ley Estatutaria 1757 de 2015 sobre participación democrática, la Corte Constitucional ha señalado su valor democrático en numerosos pronunciamientos. Así, en la Sentencia C-094 del 2017 advierte que se trata de una manifestación directa del derecho fundamental a la participación ciudadana, lo que la vuelve un valiosísimo instrumento jurídico que permite a los ciudadanos la defensa del alcance y poder normativo que tiene la Constitución Política, así como su integridad, al tiempo que pueden manifestarse deliberativa y democráticamente sobre las actuaciones que el legislador hace en ejercicio del poder de configuración de las normas que le ha otorgado la Constitución Política. De igual forma, la Sentencia C-352 de 2013 permite concluir que se trata de un mecanismo que provoca la actuación de la Corte para que produzca una providencia con efectos de cosa juzgada sobre el contenido jurídico de una decisión legislativa 
y que, en esa medida, con ello se expresa una doble dimensión: el ejercicio de un derecho político y las prerrogativas que tienen los ciudadanos para ejercer control sobre sus representantes.

Se trata de un mecanismo que desarrolla el principio democrático básico, previsto en los artículos 1, 2 y 3 de la Constitución Política, en virtud de los cuales el Estado colombiano se entiende como un Estado social de derecho, democrático y participativo (Sentencias C-113 de 2017, C-665 de 2016, C-645 de 2016 y C-128 de 2011). De igual forma, es el desarrollo del principio democrático básico, en la medida en la que expresa el carácter universal y expansivo de este (Sentencias C-150 de 2015 y C-089 de 1994). Es decir, la acción pública de inconstitucionalidad es una expresión de la necesidad de ampliar el número de los escenarios, procesos y lugares en los que se participa, pues mediante ella los ciudadanos encuentran una herramienta que les permite ensanchar el alcance de su reivindicación. Mediante esta acción, en principio, cualquier campo de la vida social puede debatirse, su única condición es que haya sido regulado mediante una norma con fuerza legislativa. Puesto que la Constitución Política tiende a regular la mayoría de los espacios personales, comunitarios y sociales en los que se desarrolla la vida de todas las personas, el control de constitucionalidad permite, en consecuencia, enjuiciar todas las normas legislativas que atenten contra esas determinaciones. Además, es una expresión del carácter expansivo de la democracia, en la medida en la que permite reivindicaciones a partir de una ampliación progresiva de las oportunidades de participación. La ciudadanía se apropia de esta herramienta, a pesar de que no esté regulada en las leyes sobre participación, porque, en la práctica, tiene el efecto de darle mayores alcances a la incidencia política.

Lo que permite el proceso constitucional es, precisamente, que los ciudadanos defiendan sus interpretaciones sobre lo que es políticamente deseable en materia fiscal, es decir, es un espacio para que el poder tributario se forme y se transforme. La jurisdicción constitucional permite que los ciudadanos ataquen normas tributarias con las que no están de acuerdo, para que salgan del ordenamiento jurídico mediante un proceso de demostración de su inconstitucionalidad. Se trata de un debate argumentativo en el que se construye un sentido políticamente deseable de la Constitución, en el que se muestra que la norma tributaria lo contradice y que, por lo tanto, debe desaparecer. 
Los ecos de las trece colonias. De los impuestos con representación a la participación...

Gráfica 1. Acciones de constitucionalidad, 1992-2017.

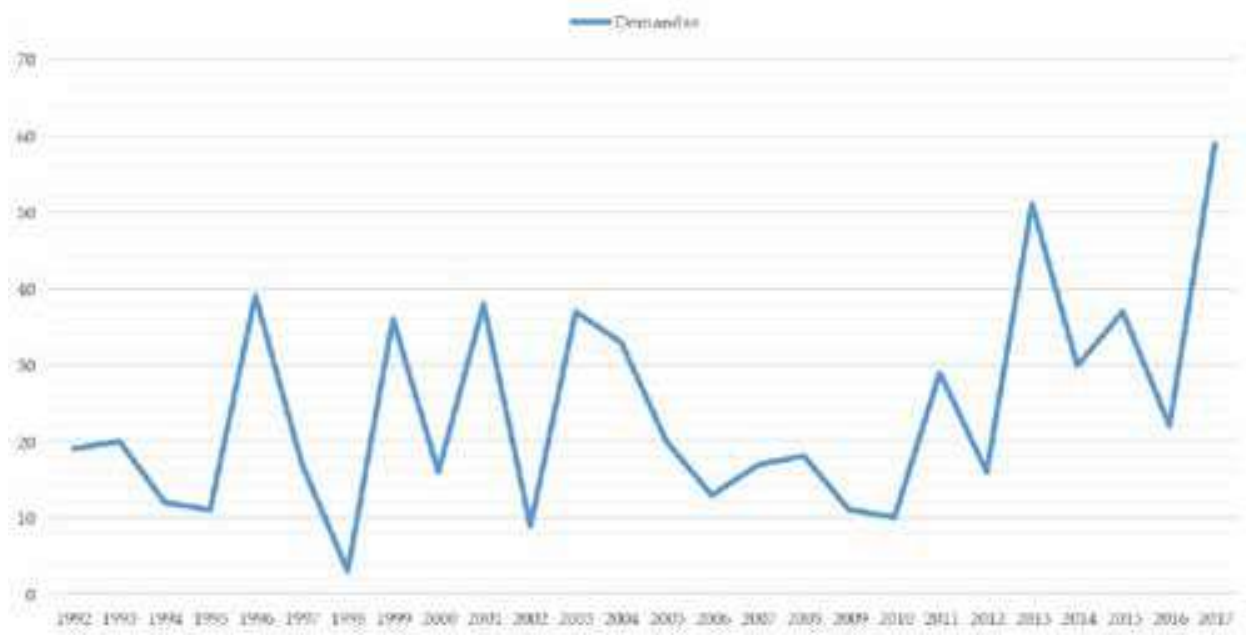

Fuente: elaboración propia a partir de Corte Constitucional (s .f.).

$\mathrm{Al}$ analizar el comportamiento de las acciones de inconstitucionalidad en contra de normas tributarias, en el caso colombiano se encuentran algunas circunstancias particularmente relevantes, que se señalan a continuación.

Sobre 37 leyes tributarias expedidas entre 1989 y 2016 los colombianos han presentado 623 acciones públicas de constitucionalidad. Los picos (1996, 1999, 2001, 2003, 2011, 2015 y 2017) obedecen a que el año inmediatamente anterior se promulgó una reforma estructural. ${ }^{1}$ Aunque no se observa ninguna tendencia clara, sí llama la atención el alto número de demandas que se presentaron en 2017. Una posible interpretación es que la reforma que se hizo el año anterior tuvo un alto grado de visibilidad pública gracias, en buena parte, a que el desescalamiento del conflicto con las FARC ha permitido abrir la agenda a nuevas temáticas.

\footnotetext{
${ }^{1}$ Es decir, aquellas leyes que han tocado temas sensibles en cuanto a definición de bases gravables, bienes y servicios susceptibles de ser objeto de tributo, entre otras; especialmente aquellas reformas que han recibido esta denominación por parte de la opinión pública y los representantes gubernamentales. Algunas de estas reformas tributarias son: Ley 6 de 1992; Ley 223 de 1995; Ley 488 de 1998; Ley 633 de 2000; Ley 788 de 2002; Ley 863 de 2003; Ley 1111 de 2006; Ley 1370 de 2009; Ley 1430 de 2010; Ley 1607 de 2012; Ley 1739 de 2014; Ley 1819 de 2016.
} 
Ahora, no solo es necesario saber cuántas demandas se han presentado, sino que se debe revisar cuál ha sido su eficacia, es decir, qué porcentaje de acciones terminan con el cumplimiento de su objetivo, que es la destrucción - declaratoria de inexequibilidad - de las normas tributarias demandadas. Para ello, las decisiones se han clasificado en ocho categorías diferentes, cada una de las cuales se refiere a un resultado procesal posible.

Así, la inconstitucionalidad se refiere a aquellos casos en los que se ha declarado que la norma es contraria a la Constitución y que, por lo tanto, se entiende como eliminada del ordenamiento jurídico. Por otra parte, la condicionalidad se refiere a los casos en los que después de un análisis de varios de los sentidos que puede tener una norma la Corte determina cuál de esos sentidos es constitucional y cuál no, es decir, se determina cómo debe interpretarse la norma para que permanezca teniendo efectos jurídicos. La constitucionalidad hace referencia a los casos en los que la norma se ajusta a la Constitución, así que continúa operando con toda su fuerza. En cuanto a la cosa juzgada, se refiere a los eventos en los que la Corte ya se ha pronunciado sobre la constitucionalidad de una norma frente a unos cargos determinados, razón por la cual se considera que ya ha habido un pronunciamiento que, por seguridad jurídica, no debe rehacerse. Este resultado difiere del de inhibición,

[ 96 ] en el que la Corte determina que la demanda no fue lo suficientemente clara y técnicamente formulada como para poderse analizar. Finalmente, los resultados de archivo, en trámite y acumulado se refieren a momentos puramente procesales de la revisión: el primero, cuando la Corte «cierra» el proceso de revisión, principalmente cuando no se subsanan los vicios en la presentación de la demanda; el segundo, cuando el proceso de revisión está operando; y el último, cuando varias demandas se agrupan bajo un mismo proceso, por compartir unidad jurídica en las normas y los cargos.

\subsection{Demandas Estatuto Tributario versus demandas a reformas}

Al hacer una comparación entre las demandas al Estatuto Tributario (ET) y las demandas a sus principales reformas, la efectividad de las acciones en contra de estas últimas es mucho mayor. Mientras que tan solo 2,9\% de las demandas al ET terminan en una sentencia favorable - de inexequibilidad-, cerca de $13 \%$ de las demandas a las reformas consiguen que los artículos demandados salgan del ordenamiento jurídico. Es decir, parece ser más probable destruir artículos de las reformas que del ET. Sin embargo, hay 
Los ecos de las trece colonias. De los impuestos con representación a la participación...

que resaltar el alto nivel de archivo que se generan frente a estas acciones (30\%). La decisión de archivo se produce cuando, después de presentada la demanda, la Corte Constitucional encuentra que tiene vicios que no permiten su análisis. Se da un plazo para que esos vicios se corrijan, y si no se logra se archiva. Al tratarse de temas muy técnicos, puede ser particularmente difícil para la ciudadanía estructurar demandas que se ajusten a los requerimientos mínimos que exige la jurisdicción constitucional, y puede ser por esto que se produce tan elevado porcentaje de archivo.

Gráfica 2. Comparación entre demandas al Estatuto Tributario (ET) y demandas a sus principales reformas.

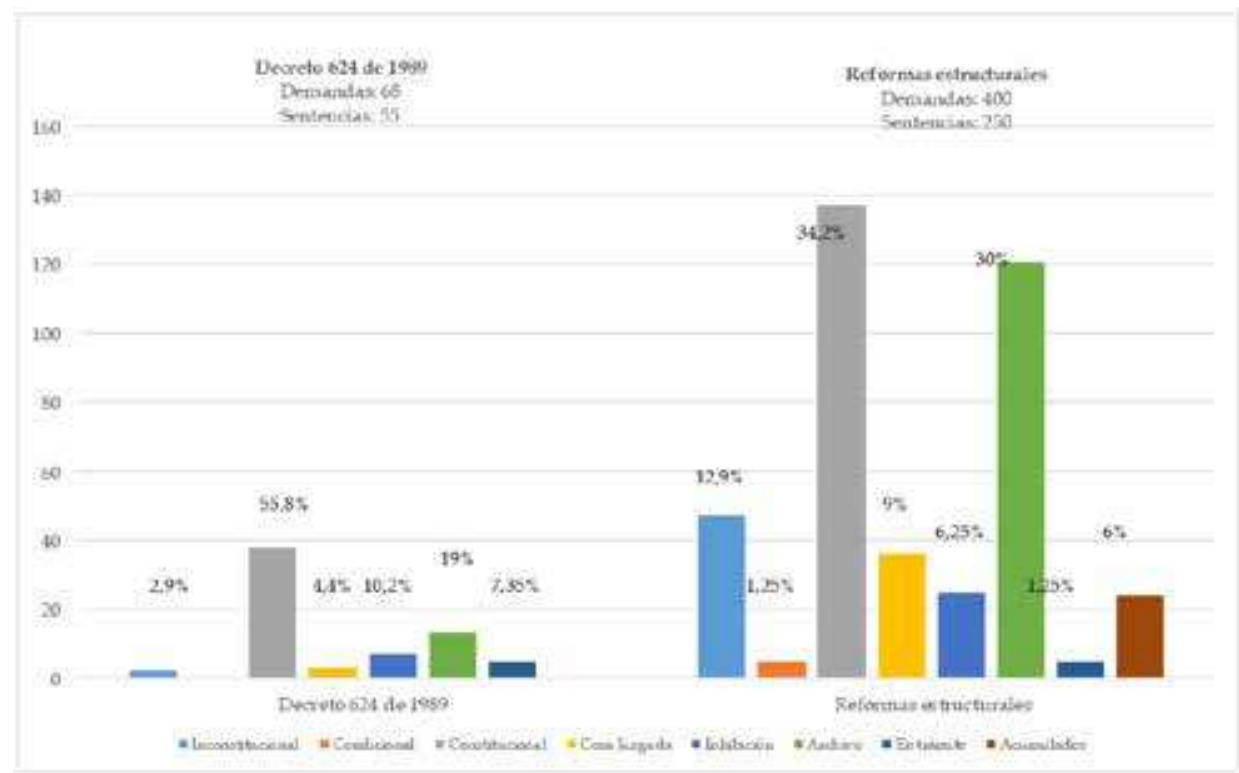

Fuente: elaboración propia a partir de Corte Constitucional (s. f.).Dada la complejidad del tema, el papel de actores como las universidades y los centros de estudio y pensamiento tendría que ayudar a orientar el proceso de revisión constitucional. De hecho, la Corte Constitucional, en cada demanda, invita a estas instituciones para que conceptúen sobre la discusión. Al observar en detalle los procesos de revisión de las dos últimas reformas estructurales, los porcentajes de participación, en el caso de las universidades, es muy bajo. En el caso de otros actores de la sociedad civil -ONG, centros de pensamiento, asociaciones gremiales, entre otros-, la participación no pasa de 50\%. Es decir, los actores cualificados de la sociedad civil se están absteniendo de utilizar las herramientas de la democracia participativa para darle bases constitucionales firmes a la capacidad fiscal del Estado. 
Gráfica 3. Participación de la sociedad civil

en el proceso de revisión constitucional.

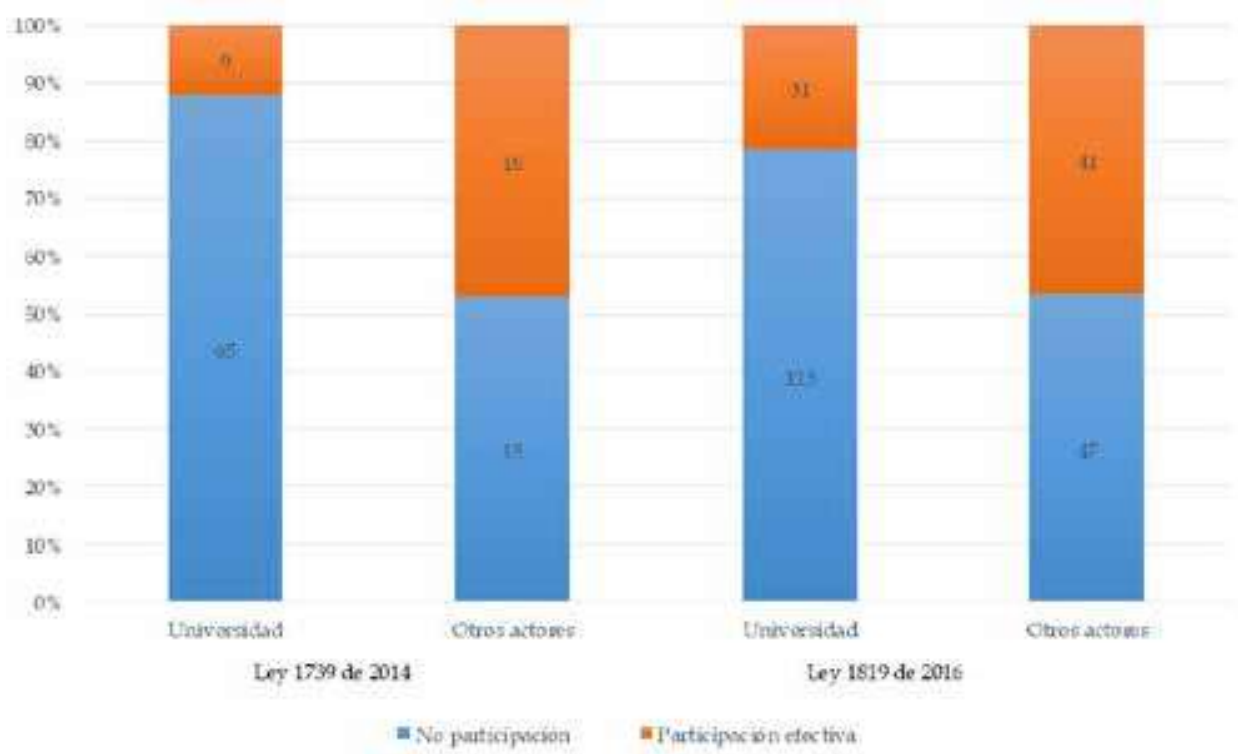

Fuente: elaboración propia a partir de Corte Constitucional (s. f.).En el caso de la Ley 1739,

las universidades recibieron 74 invitaciones a participar en los diferentes procesos; sin embargo, solo en 9 oportunidades se envió un concepto técnico. En cuanto a la Ley 1819, de las 144 invitaciones las universidades solo participaron en 31 oportunidades. La voz de los actores más calificados ha sido débil. Al tratarse de un tema que requiere de conocimientos técnicos precisos que van más allá de lo jurídico y que pasan por lo político y económico, los magistrados de la Corte Constitucional —abogados de formación-, buscan constante apoyo en entidades cuyo conocimiento técnico es reconocido en el ámbito nacional. A pesar de esto, ese aporte ha sido tenue. Si se asume que el proceso de revisión de la constitucionalidad de las normas tributarias está atravesado por el objetivo de lograr que la configuración de la capacidad fiscal del Estado se ajuste a criterios de conveniencia técnica y política, el inconsistente apoyo de la academia no le ha aportado a ese equilibrio.

\section{Discusión}

El concepto de «sociedad civil» puede llegar a ser de muy difícil definición. Por ello, determinar hasta qué punto la acción pública de constitucionalidad ha permitido que la sociedad civil intervenga de una forma más efectiva en la definición de la política y de la capacidad fiscal del Estado colombiano pasa por el obstáculo de identificar qué fragmentos y sectores de la sociedad civil han hecho uso de las posibilidades de este 
mecanismo. Lo que los resultados muestran, en principio, es que han sido actores sociales por fuera del espacio de la academia quienes han jalonado este tipo de procesos. Esto supone un hecho que podría ir contra el sentido común: puede pensarse, razonablemente, que al tratarse de cuestiones que frecuentemente involucran temáticas muy técnicas, las universidades tendrían un papel mucho más relevante; sin embargo, su papel ha sido limitado. Esta idea fortalece el presupuesto teórico de que los mecanismos de participación ciudadana ayudan a derrumbar el mito de la neutralidad de la política fiscal. Si en realidad fuera una política neutra, los actores técnicos y neutros serían los protagonistas, sin embargo, las acciones públicas han sido presentadas por distintos actores y, particularmente en los procesos de participación abiertos al público — cuando la Corte solicita conceptos-, actores distintos a la academia.

Más allá de quiénes son los actores que jalonan estos procesos, los resultados muestran mayores niveles de participación en las discusiones constitucionales sobre política fiscal. Si bien debe hacerse una revisión futura, para ver si el nivel de acciones se mantiene, lo cierto es que el pico histórico logrado en 2017 señala que la política fiscal es un ámbito de debate público cada vez más relevante para los colombianos. Las discusiones sobre la nueva ley de financiamiento y su eventual aprobación constituirán un agitado debate que debe tenerse en el radar. En este sentido, otro de los principales hallazgos, que merece mayor atención, es el hecho de que sean las leyes de reforma las que tengan más altos niveles de efectividad en la declaratoria de inconstitucionalidad, mientras que las normas base del estatuto tributario registran menos efectividad. Este hecho puede interpretarse bajo la perspectiva de que los mecanismos de participación ciudadana en política fiscal ayudan a derrumbar el falso presupuesto de la neutralidad política. En efecto, las reformas a las leyes tributarias suelen estar rodeadas de fuertes discusiones en las que intereses políticos se ponen en disputa. Es probable que para la opinión pública el Estatuto Tributario se presente como un conjunto de normas técnicas que regulan la distribución de las imposiciones fiscales, mientras que las reformas tributarias se convierten en un terreno de disputa en el que se deciden ganadores y perdedores.

En esto es clave el papel que tienen los medios de comunicación en la presentación sobre dichas reformas, pues es a partir de la información que ellos transmiten se construye una narrativa politizada de los cambios en la política fiscal, es decir, los medios no transmiten información sobre el Estatuto 
Tributario, ni hacen informes sobre su contenido. Las noticias en relación con la política fiscal se activan en la medida en la que se introducen discusiones para transformarla y en la medida en la que diversos actores políticos debaten sobre ellas en espacios de opinión, en medios radiales y televisivos, y en espacios de prensa.

\section{Conclusiones}

La democracia participativa ha abierto una puerta para que cuestiones tributarias y fiscales sean directamente debatidas y atacadas por los ciudadanos, sin que tengan estos que someterse a las «interpretaciones» que los representantes hagan de sus voluntades. La declaración de las Trece Colonias, la idea de que ninguna contribución fiscal debe ser impuesta sin consentimiento encuentra hoy, además de la garantía de la representación, una forma adicional de ser materializada a través de la participación directa. Esta, por supuesto, es una forma optimista de abordar la cuestión: evidentemente, las herramientas jurídicas tienen limitaciones. La jurisdicción constitucional, como campo de batalla, no permite la lucha de todos los soldados. Las exigencias técnicas hacen que una porción significativa de las acciones de los ciudadanos no produzca ningún efecto.

En ese sentido, actores calificados como las universidades, están llamados a introducirse en este campo de disputa. El conocimiento técnico que allí se produce debería guiar el proceso de mejoramiento de la capacidad fiscal. Así, el esfuerzo conjunto de la academia y otros actores de la sociedad civil podrían apuntarle a la tarea nunca acabada de construir Estado en Colombia.

\section{Referencias bibliográficas}

1. Alstott, Anne. (1996). Tax Policy and Feminism: Competing Goals and Institutional Choices. Columbia Law Review, 96 (8), pp. 2001-2082. https://doi. org/10.2307/1123417

2. Asamblea Nacional Constituyente (ANC). (1991, febrero 18). Gaceta Constitucional, 7. Recuperado de http://abogadosrosaristas.org.co/2016/2016/10/19/ gacetas-constitucionales/?drawer $=$ gacetas $*$ Gaceta $\%$ 20Constitucional $\% 20 \mathrm{Tomo} \% 20$ 001\%20a\%20025-1991*Gaceta\% 20Constitucional\%20Tomo\%2007-1991

3. Asamblea Nacional Constituyente (ANC). (1991, febrero 19a). Gaceta Constitucional, 8. Recuperado de http://abogadosrosaristas.org.co/2016/2016/10/19/ 
Los ecos de las trece colonias. De los impuestos con representación a la participación...

gacetas-constitucionales/?drawer $=$ gacetas* Gaceta $\% 20$ Constitucional $\% 20$ Tomo $\% 20$ 001\%20a\%20025-1991*Gaceta\%20Constitucional\%20Tomo\%2008-1991

4. Asamblea Nacional Constituyente (ANC). (1991, febrero 19b). Gaceta Constitucional, 9. Recuperado de http://abogadosrosaristas.org.co/2016/2016/10/19/ gacetas-constitucionales/?drawer $=$ gacetas $*$ Gaceta $\% 20$ Constitucional $\% 20$ Tomo $\% 20$ 001\%20a\%20025-1991*Gaceta\%20Constitucional\%20Tomo\%2009-1991

5. Asamblea Nacional Constituyente (ANC). (1991, marzo 4). Gaceta Constitucional, 15. Recuperado de http://abogadosrosaristas.org.co/2016/2016/10/19/ gacetas-constitucionales/?drawer = gacetas*Gaceta $\% 20$ Constitucional $\% 20$ Tomo $\% 20$ 001\%20a\%20025-1991*Gaceta\%20Constitucional\%20Tomo\%2015-1991

6. Asamblea Nacional Constituyente (ANC). (1991, marzo 5). Gaceta Constitucional, 16. Recuperado de http://abogadosrosaristas.org.co/2016/2016/10/19/ gacetas-constitucionales/?drawer $=$ gacetas $*$ Gaceta $\% 20$ Constitucional $\% 20$ Tomo $\% 20$ 001\%20a\%20025-1991*Gaceta\%20Constitucional\%20Tomo\%2016-1991

7. Asamblea Nacional Constituyente (ANC). (1991, marzo 15). Gaceta Constitucional, 21. Recuperado de http://abogadosrosaristas.org.co/2016/2016/10/19/ gacetas-constitucionales/?drawer = gacetas $*$ Gaceta $\% 20$ Constitucional $\% 20$ Tomo $\% 20$ 001\%20a\%20025-1991*Gaceta\%20Constitucional\%20Tomo\%2021-1991

8. Asamblea Nacional Constituyente (ANC). (1991, mayo 4). Gaceta Constitucional, 67. Recuperado de http://abogadosrosaristas.org.co/2016/2016/10/19/ gacetas-constitucionales/?drawer = gacetas*Gaceta $\% 20$ Constitucional $\% 20$ Tomo $\% 20$ 051\%20a\% 20075-1991*Gaceta\%20Constitucional\%20Tomo\%2067-1991

9. Bonanno, Alessandro. (2000). The Crisis of Representation: The Limits of Liberal Democracy in the Global Era. Journal of Rural Studies, 16 (3), pp. 305-323. https://doi.org/10.1016/S0743-0167(99)00064-9

10. Cain, Patricia. (1991). Same-Sex Couples and the Federal Tax Laws. Law \& Sexuality, 100, pp. 97-131.

11. Clark, Meri. (2007). Conflictos entre el Estado y las élites locales sobre la educación colombiana durante las décadas de 1820-1830. Historia Crítica, 34, pp. 32-61. https://doi.org/10.7440/histcrit34.2007.02

12. Colombia. Congreso. Ley 6. (30 de junio de 1992). Por la cual se expiden normas en materia tributaria, se otorgan facultades para emitir títulos de deuda pública interna, se dispone un ajuste de pensiones del sector público nacional y se dictan otras disposiciones. Recuperado de http://www.secretariasenado.gov.co/senado/basedoc/ ley_0006_1992.html

13. Colombia. Congreso. Ley 134. (31 de mayo de 1994). Por la cual se dictan normas sobre mecanismos de participación ciudadana. Recuperado de http://www. secretariasenado.gov.co/senado/basedoc/ley_0134_1994.html

14. Colombia. Congreso. Ley 223. (20 de diciembre de 1995). Por la cual se expiden normas sobre racionalización tributaria y se dictan otras disposiciones. 
Recuperado de http://www.secretariasenado.gov.co/senado/basedoc/ley_0223_1995. html

15. Colombia. Congreso. Ley 488. (24 de diciembre de 1998). Por la cual se expiden normas en materia tributaria y se dictan otras disposiciones fiscales de las Entidades Territoriales. Recuperado de http:/www.secretariasenado.gov.co/senado/ basedoc/ley_0488_1998.html

16. Colombia. Congreso. Ley 633. (29 de diciembre de 2000). Por la cual se expiden normas en materia tributaria, se dictan disposiciones sobre el tratamiento de los fondos obligatorios para la vivienda de interés social y se introducen normas para fortalecer las finanzas de la Rama Judicial. Recuperado de http://www.funcionpublica. gov.co/eva/gestornormativo/norma.php?i $=6285$

17. Colombia. Congreso. Ley 788. (27 de diciembre de 2002). Por la cual se expiden normas en materia tributaria y penal del orden nacional y territorial; y se dictan otras disposiciones. Recuperado de http://www.secretariasenado.gov.co/ senado/basedoc/ley_0788_2002.html

18. Colombia. Congreso. Ley 863. (29 de diciembre de 2003). Por la cual se establecen normas tributarias, aduaneras, fiscales y de control para estimular el crecimiento económico y el saneamiento de las finanzas públicas. Recuperado de http://www.secretariasenado.gov.co/senado/basedoc/ley_0863_2003.html

19. Colombia. Congreso. Ley 1111. (27 de diciembre de 2006). Por la cual se modifica el estatuto tributario de los impuestos administrados por la Dirección de [102] Impuestos y Aduanas Nacionales. Recuperado de http://www.secretariasenado.gov. co/senado/basedoc/ley_1111_2006.html

20. Colombia. Congreso. Ley 1370. (30 de diciembre de 2009). Por la cual se adiciona parcialmente el estatuto tributario. Recuperado de http://www. secretariasenado.gov.co/senado/basedoc/ley_1370_2009.html

21. Colombia. Congreso. Ley 1430. (29 de diciembre de 2010). Por medio de la cual se dictan normas tributarias de control y para la competitividad. Recuperado de http://www.secretariasenado.gov.co/senado/basedoc/ley_1430_2010.html

22. Colombia. Congreso. Ley 1607. (10 de enero de 2012). Por la cual se establece la distribución de competencias entre las entidades del Estado en materia de televisión y se dictan otras disposiciones. Recuperado de http://www.secretariasenado.gov.co/ senado/basedoc/ley_1507_2012.html

23. Colombia. Congreso. Ley 1739. (23 de diciembre de 2014). Por medio de la cual se modifica el Estatuto Tributario, la Ley 1607 de 2012, se crean mecanismos de lucha contra la evasión y se dictan otras disposiciones. Recuperado de http://www. secretariasenado.gov.co/senado/basedoc/ley_1739_2014.html

24. Colombia. Congreso. Ley 1757. (6 de julio de 2015). Por la cual se dictan disposiciones en materia de promoción y protección del derecho a la participación democrática. Recuperado de http://www.secretariasenado.gov.co/senado/basedoc/ ley_1757_2015.html 
Los ecos de las trece colonias. De los impuestos con representación a la participación...

25. Colombia. Congreso. Ley 1819. (29 de diciembre de 2016). Por medio de la cual se adopta una reforma tributaria estructural, se fortalecen los mecanismos para la lucha contra la evasión y la elusión fiscal, y se dictan otras disposiciones. Recuperado de http://www.secretariasenado.gov.co/senado/basedoc/ley_1819_2016.html

26. Colombia. Corte Constitucional. Sentencia C-089. (3 de marzo de 1994). Recuperado de http://www.corteconstitucional.gov.co/relatoria/1994/C-089-94.htm

27. Colombia. Corte Constitucional. Sentencia C-128. (2 de marzo de 2011). Recuperado de http://www.corteconstitucional.gov.co/relatoria/2011/C-128-11.htm

28. Colombia. Corte Constitucional. Sentencia C-352. (19 de junio de 2013). Recuperado de http://www.corteconstitucional.gov.co/RELATORIA/2013/C-352-13. htm

29. Colombia. Corte Constitucional. Sentencia C-150. (8 de abril de 2015). Recuperado de http://www.corteconstitucional.gov.co/RELATORIA/2015/C-150-15. htm

30. Colombia. Corte Constitucional. Sentencia C-645. (23 de noviembre de 2016). Recuperado de http://www.corteconstitucional.gov.co/RELATORIA/2016/C-645-16. htm

31. Colombia. Corte Constitucional. Sentencia C-665. (30 de noviembre de 2016). Recuperado de http://www.corteconstitucional.gov.co/RELATORIA/2016/C-665-16. htm

32. Colombia. Corte Constitucional. Sentencia C-094. (15 de febrero de 2017). Recuperado de http://www.corteconstitucional.gov.co/relatoria/2017/C-094-17.htm

33. Colombia. Corte Constitucional. Sentencia C-113. (22 de febrero de 2017). Recuperado de http://www.corteconstitucional.gov.co/relatoria/2017/C-113-17.htm

34. Corte Constitucional. (s. f.). Secretaría General. Procesos. Buscador web. Recuperado de http://www.corteconstitucional.gov.co/secretaria/ConsultaC/proceso. php

35. Creighton, James. (2005). The Public Participation Handbook. Making Better Decisions Through Citizen Involvement. San Francisco: Jossey-Bass.

36. Deas, Malcolm. (1980). Los problemas fiscales en Colombia durante el siglo xIx. En: Fundación para el la Educación Superior y el Desarrollo (ed.). Ensayos sobre historia económica colombiana (pp. 143-180). Bogotá, D. C.: Fedesarrollo.

37. Esguerra, Juan Carlos y Arias, Jaime. (20 de mayo de 1991). Democracia participativa. Reforma y pedagogía de la Constitución. Comisión Primera. Ponencia Subcomisión Tercera. Asamblea Nacional Constituyente. Recuperado de http://babel. banrepcultural.org/cdm/ref/collection/p17054coll28/id/249

38. Galán, Antonio. (8 de marzo de 1991). Democratización y participación popular para una efectiva canalización de los anhelos y aspiraciones, hoy reclamados en forma violenta. Proyecto 126 C. Comisión Tercera. Asamblea Nacional Constituyente. Recuperado de http://babel.banrepcultural.org/cdm/ref/collection/ p17054coll28/id/424 
39. Garcés, María Teresa. (19 de febrero de 1991). Ampliación de la democracia. Proyecto 13. Comisión Cuarta. Asamblea Nacional Constituyente Recuperado de http://babel.banrepcultural.org/cdm/ref/collection/p17054coll28/id/484

40. Gopal-Jayal, Niraja. (2009). The Limits of Representative Democracy. South Asia: Journal of South Asian Studies, 32 (3), pp. 327-337.

41. Guzmán, Alejandro. (2011). Democracia participativa en Colombia: Un sueño veinte años después. Revista Jurídicas, 8 (2), pp. 30-41.

42. Huntington, Samuel. (1991). The Third Wave: Democratization in the Late 20th Century. Norman: University of Oklahoma.

43. Irigoin, Alejandra. (2016). Representation without Taxation, Taxation without Consent: The Legacy of Spanish Colonialism in America. Journal of Iberian and Latin American Economic History, 34 (2), pp. 169-208. https://doi.org/10.1017/ S0212610916000069

44. Kalmanovitz, Salomón. (2016). El orden social y la construcción de Estado en Colombia. Manuscrito inédito.

45. Knauer, Nancy. (1998). Heteronormativity and Federal Tax Policy. West Virginia Law Review, 101, pp. 130-234.

46. Knauer, Nancy. (2014). Critical Tax Policy: A Pathway to Reform? Northwestern Journal of Law \& Social Policy, 9 (2), pp. 206-263.

47. Lleras de la Fuente, Carlos y Mejía, Arturo. (8 de marzo de 1991). Una constitución funcional y participativa para la democracia. Proyecto 93. Comisión

[104 ] Tercera. Asamblea Nacional Constituyente. Recuperado de http://babel.banrepcultural. org/cdm/ref/collection/p17054coll28/id/374

48. MacDonald, Keith \& Tipton, Colin. (1995). Using Documents. In: Gilbert, Nigel (ed.). Researching Social Life. Londres: Sage.

49. Mainwaring, Scott; Brinks, Daniel \& Pérez-Liñán, Aníbal. (2007). Classifying Political Regimes in Latin America, 1945-2004. In: Munck, Gerardo (ed.). Regimes and Democracy in Latin America. Theories and Methods (pp. 123-160). New York: Oxford University.

50. Marx, Karl. (2009). The Eighteenth Brumaire of Luis Napoleon. New York: Dodo.

51. Mehrotra, Ajay. (2015). Reviving Fiscal Citizenship. Michigan Law Review, 113 (6), pp. 943-972.

52. Mendieta, David. (2010). La acción pública de inconstitucionalidad: a propósito de los 100 años de su vigencia en Colombia. Vniversitas, 120, pp. 61-84.

53. Moran, Beverly \& Whitford, William. (1997). A Black Critique of the Internal Revenue Code. Wisconsin Law Review, 1996, pp. 751-820.

54. Morgen, Sandra y Erickson, Jennifer. (2017). Incipient «Commoning» in Defense of the Public? Competing Varieties of Fiscal Citizenship in Tax and SpendingRelated Direct Democracy. Focaal. Journal of Global and Historical Anthropology, 79, pp. 54-66. 
Los ecos de las trece colonias. De los impuestos con representación a la participación...

55. Murphy, Liam \& Nagel, Thomas. (2002). The Myth of Ownership. Taxes and Justice. New York: Oxford University. https://doi.org/10.1093/0195150163.001.0001

56. Navarro Wolff, Antonio et al. (7 de marzo de 1991). Derechos, garantías y deberes fundamentales, título III. Proyecto 50. Comisión Tercera. Asamblea Nacional Constituyente. Recuperado de http://babel.banrepcultural.org/cdm/ref/collection/ p17054coll28/id/470

57. Palacios, Marco. (1980). La fragmentación regional de las clases dominantes: una perspectiva histórica. Revista Mexicana de Sociología, 42 (4), pp. 1663-1689. https://doi.org/10.2307/3539965

58. Pimbert, Michel y Wakefort, Tom. (2001). Overview: Deliberative Democracy and Citizen Empowerment. PLA Notes, 40, pp. 23-28.

59. Publimetro. (2017, noviembre 11). Video: hombre se niega a pagar IVA en el Éxito porque con ese dinero «van a comprarle aviones a Timochenko». Recuperado de http://bit.ly/2ztOFCO

60. Ross, Michael. (2004). Does Taxation Lead to Representation? British Journal of Political Science, 34 (2), pp. 229-249. https://doi.org/10.1017/S0007123404000031

61. Rowe, Gene \& Frewer, Lynn. (2005). A Typology of Public Engagement Mechanisms. Science, Technology, \& Human Values, 30 (2), pp. 251-290. https://doi. org/10.1177/0162243904271724

62. Schmitter, Philippe \& Karl, Terry. (1991). What Democracy is... and is Not. Journal of Democracy, 2 (3), pp. 75-88. https://doi.org/10.1353/jod.1991.0033

63. Schweber, Howard. (2016). The Limits of Political Representation. American Political Science Review, 110 (2), pp. 382-396. https://doi.org/10.1017/ S0003055416000137

64. Seto, Theodore \& Buhai, Sande. (2006). Tax and Disability: Ability to Pay and the Taxation of Difference. University of Pennsylvania Law Review, 154, pp. 10531145. https://doi.org/10.2307/40041320

65. Stubbs, William. (1895). The Constitutional History of England, Vol. II. Oxford: Clarendon.

66. Trujillo, Carlos Holmes. (8 de marzo de 1991). De la naturaleza del Estado con un Estado de participación democrática y social. Proyecto 54. Comisión Segunda. Asamblea Nacional Constituyente. Recuperado de http://www.banrepcultural.org/ blaavirtual/ANC/brblaa857243.pdf

67. Uribe, María Teresa. (1995). Lo viejo y lo nuevo en la crisis política colombiana. Estudios Políticos, 07-08, pp. 78-90.

68. Valencia, Hernando. (1987). Cartas de batalla. Una crítica del constitucionalismo colombiano. Bogotá, D. C.: Cerec. 